\title{
THE ULTRASOUND-GUIDED MULTIPLE-INJECTION COSTOTRANSVERSE BLOCK FOR POSTOPERATIVE PAIN MANAGEMENT WITH MAJOR BREAST CANCER SURGERY: \\ CASE REPORTS
}

\author{
Martin Vedel Nielsen, Katrine Bayer Tanggaard, Jens Børglum \\ Department of Anaesthesiology and Intensive Care Medicine, Zealand University Hospital, University of Copenhagen, Denmark \\ martinvedel@gmail.com
}

\begin{abstract}
Background and aim
The multiple-injection costotransverse block (MICB) ${ }^{1}$ combines the positive mechanism of action from the thoracic paravertebral block with a reduced risk profile and we have, with success, obtained postoperative pain management with MICB for both unilateral mastectomy with sentinel node biopsy and bilateral mastectomy with primary reconstructive surgery (BMPR). We present three pilot cases (patients' oral and written informed consent obtained).
\end{abstract}

\section{Methods}

Preoperative multimodal analgesic regime for all patients consisted of Acetaminophen 1g, Celecoxib 400mg, Gabapentin 600mg, Dexamethasone 8mg and Dextromethorphan 30mg. The MICB was successfully applied preoperatively at levels T2, T4, T6 and 30min. prior to emergence 10 $\mathrm{gg}$ Sufentanil was administered (case C $12 \mu \mathrm{g}$ Sufentanil)

Case A: A 56-year-old woman, weight $68 \mathrm{~kg}$ (body mass index, $24.1 \mathrm{~kg} / \mathrm{m}^{2}$ ) with a history of thrombocytopenic purpura, hypertension and poor morphine tolerance (syncope), scheduled for unilateral mastectomy and sentinel node biopsy due to breast cancer. MICB: Ropivacaine $0.5 \%, 3 \times 10 \mathrm{ml}$ respectively. A PECS1 block ${ }^{2}$ using Ropivacaine $0.375 \% 10 \mathrm{ml}$ block was added.

Case B: A 67-year-old woman, weight $55 \mathrm{~kg}$ (body mass index, $23.2 \mathrm{~kg} / \mathrm{m}^{2}$ ) with a history of chronic obstructive pulmonary disease scheduled for BMPR due to breast cancer. Bilateral MICB: Ropivacaine $0.375 \% 6 \times 10 \mathrm{ml}$ supplemented with $60 \mu \mathrm{g}$ Dexmedetomidine.

Case C: A 51-year-old woman, weight $57 \mathrm{~kg}$ (body mass index, $21.5 \mathrm{~kg} / \mathrm{m}^{2}$ ) with a history of migraine and gastroesophageal reflux scheduled for UMPR with a sub-pectoral implant due to breast cancer. MICB: Ropivacaine $0.75 \% 3 \times 7 \mathrm{ml}$.

\section{Results}

Case A: Oral Tradolan 100mg was administered within the first $24 \mathrm{hrs}$. Reported diplopia $12 \mathrm{hrs}$. postoperative; presumably from sympathetic block.

Case B: Sufentanil $10 \mu \mathrm{g}$ and Morphine $5 \mathrm{mg}$ was administered within the first $24 \mathrm{hrs}$. (all in the post anaesthesia care unit). Left surgical field was completely pain free.

Case C: In the PACU the patient received $5 \mathrm{mg}$ morphine and $5 \mathrm{mcg}$ Sufentanil. No opioids were administered within $48 \mathrm{hrs}$. of discharge from the PACU. The patient reported no adverse effects in regards to the MICB.

\section{Conclusion}

The MICB is effective as postoperative pain management in regards to major breast cancer surgery. In a forthcoming RCT we aim to use Ropivacaine $0.5 \% 3 \times 10 \mathrm{ml}$ at levels T2, T4, T6 respectively and $0.2 \mathrm{mcg}$ Sufentanil/kg body weight $30 \mathrm{~min}$. prior to emergence vs. placebo (saline) in 36 UMPR patients.

1. Nielsen M V, Moriggl B, Hoermann R, Nielsen TD, Bendtsen TF, Børglum J. Are Single-injection Erector Spinae Plane Block and Multiple-injection Costotransverse Block Equivalent to Thoracic Paravertebral Block? Acta Anaesthesiol Scand. 2019;Accepted:In press.

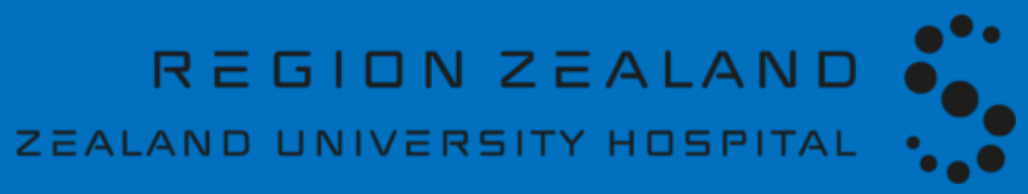

